\title{
Elecciones locales en Ecuador: cambios y constantes
}

Jorge León Trujillo

\section{(2) OpenEdition}

Journals

Edición electrónica

URL: http://journals.openedition.org/bifea/5767

DOI: $10.4000 /$ bifea. 5767

ISSN: 2076-5827

Editor

Institut Français d'Études Andines

Edición impresa

Fecha de publicación: 1 agosto 2004

Paginación: 385-390

ISSN: 0303-7495

\section{Referencia electrónica}

Jorge León Trujillo, "Elecciones locales en Ecuador: cambios y constantes », Bulletin de l'Institut

français d'études andines [En línea], 33 (2) | 2004, Publicado el 08 abril 2004, consultado el 02

diciembre 2020. URL : http://journals.openedition.org/bifea/5767 ; DOI : https://doi.org/10.4000/bifea. 5767

\section{(c) $(7)$}

Les contenus du Bulletin de l'Institut français d'études andines sont mis à disposition selon les termes de la licence Creative Commons Attribution - Pas d'Utilisation Commerciale - Pas de Modification 4.0 International. 
Bull. Inst. fr. études andines

2004, 33 (2): 385-390

\title{
ELECCIONES LOCALES EN ECUADOR: CAMBIOS Y CONSTANTES
}

\author{
Jorge LEÓN TRUJILLO*
}

El 17 de octubre 2004, Ecuador tuvo elecciones intermedias entre las presidenciales para elegir representantes al nivel de los gobiernos locales e intermedios (o seccionales) (1).

En este análisis identificamos constantes en el comportamiento electoral ecuatoriano e indicios de cambios en su vida política relacionada con las elecciones.

\section{VICTORIAS SIMBÓLICAS}

Los resultados no definen cambios sustantivos en las tendencias políticas partidarias. No obstante, la mayoría de las organizaciones políticas se considera ganadora. Nada sorprendente en un sistema partidario tan fraccionado como el ecuatoriano (en promedio 12 partidos llegan al Congreso y el mayoritario no logra $20 \%$ de los votos o $25 \%$ de los escaños). En esta ocasión, el partido mayoritario, el líder de los de la derecha, el PSC (Partido Social Cristiano) obtiene $14 \%$ de los votantes registrados y cerca del $25 \%$ de los votos reales (2).

Cada cual mira su "victoria" en función de limitados cálculos: haber obtenido el mínimo de votos para no perder su reconocimiento legal, no haber perdido su circunscrito espacio electoral, haber logrado más que el contrincante en su mismo espacio y haber incrementado su votación o número de electos - aunque fuese en reducidas proporciones- en función de las próximas elecciones presidenciales.

\section{RESULTADOS ELECTORALES Y OPOSICIÓN GUBERNAMENTAL}

La tendencia de las elecciones intermedias ha sido que el partido de gobierno logre un resultado ventajoso. Sin embargo, a pesar de que el partido del presidente Gutiérrez (Partido Sociedad Patriótica, PSP) haya obtenido el porcentaje mínimo para

\footnotetext{
* CEDIME: Centro de Investigación de los Movimientos Sociales del Ecuador. E-mail: jorle@ecuanex.net.ec

(1) 22 prefectos provinciales; 91 consejeros provinciales; 219 alcaldes municipales; 893 concejales municipales, 3 980miembros de las juntas parroquiales de 1162 parroquias, electos por 8643974 electores(as) (50,44\% mujeres).

(2) Los datos definitivos tardan en llegar, pero hemos retomado los datos hasta ahora disponibles en el Tribunal Supremo Electoral o alternativamente, los de Carlos Larrea y Raúl Borja.
} 
mantener su reconocimiento legal (5\%), el resultado ha sido considerado negativo para él ya que ha sido el principal protagonista de esta campaña, promocionando su partido en todo el país y poniendo su gestión como la garantía para obtener una gran mayoría. Su débil resultado es visto como un plebiscito en su contra. En los sondeos, su popularidad ha caído al $8 \%$.

El uso electoral de bienes públicos, la promoción de candidatos PSP por parte del presidente y su chantaje a la población arguyendo que, a diferencia de los otros candidatos, los electos de su partido dispondrán de fondos para las obras que ellos prometan, ha sido el pretexto buscado para concretar la idea de su destitución. Sin embargo, las encuestas indican que luego de destituir a dos presidentes en los últimos 8 años y constatar los efectos negativos de la inestabilidad, la población no está entusiasta con la idea, a pesar de su acuerdo con sancionar el abuso de los recursos públicos. En el sistema presidencial, empero, no hay posibilidad de otra sanción que la destitución.

\section{RESULTADOS ELECTORALES Y SISTEMA PARTIDARIO DE MINORÍAS}

Los resultados electorales muestran la persistencia del tradicional fraccionamiento político ecuatoriano regionalizado: mientras que en la Sierra gana el centro y la izquierda, en la Costa lo hacen la derecha y el populismo.

El voto del centro y centro izquierda es más fraccionado que el de las otras tendencias. Esto repercute en su acceso a un menor número de puestos electos.

A pesar del fraccionamiento, un bloque de 6 partidos sigue recibiendo el porcentaje mayoritario de votos: PSC, ID, PRE, DP, MUPP, MPD además ahora del PRIAN ( $c f$. cuadro).

Los puestos logrados siguen el orden de importancia de los votos logrados, salvo para el PRIAN. Aparece también el PSP con 22 alcaldías pequeñas. La ID, segundo partido más votado, no logra similares resultados al nivel de puestos ya que su voto está más concentrado en ciudades serranas más pobladas. ElPSC tiene numerosos municipios pequeños, mayoritariamente en la región costera.

\section{TENDENCIAS POLÍTICAS Y TRANSFERENCIAS DE ELECTORADO}

Los cambios entre las tendencias no son enormes a pesar de que el PSC incrementa su predominio en la Costa y la ID en la Sierra. Empero, el PSC ha logrado insertarse en algunas pequeñas municipalidades de la Sierra lo que no fue el caso de la ID en la región costera.

Existen más bien reacomodos al interior de cada tendencia. En el populismo, el PRIAN disputa más espacios al PRE. En el centro, la ID (socialdemócrata) logra mejores resultados en detrimento del centro-derecha representado por la DP-UDC (demócrata-cristiana) ahora fraccionado y con poca credibilidad como efecto de su desacreditado gobierno de Mahuad. En la izquierda, el MPD ratifica su acervo electoral mientras que el PS-FA (unión de tendencias socialistas y excomunistas) se confina desde hace años con una simbólica presencia.

Los partidos populistas, PRIAN y PRE, mantienen un porcentaje de votos en la región costera. El PRE, sin embargo, ha perdido plazas fuertes mientras el PRIAN crece 


\begin{tabular}{|c|c|c|c|c|c|c|}
\hline \multirow{2}{*}{$\begin{array}{l}\text { Elecciones seccionales } 2004 \\
\text { Partidos u otra organización política }\end{array}$} & \multicolumn{3}{|c|}{ Votos logrados/partido (3) } & \multicolumn{3}{|c|}{ Puestos logrados/ partid.(4) } \\
\hline & Vot. Pref. & $\%$ & $\begin{array}{c}\% \text { Voto } \\
\text { alcald. (5) }\end{array}$ & $\begin{array}{l}\text { Pre- } \\
\text { fectos }\end{array}$ & Alcaldes & $\begin{array}{c}\text { Total } \\
\text { puestos }\end{array}$ \\
\hline PSC (Partido Social Cristiano) & 965382 & 21,3 & 25,6 & 4 & 58 & 62 \\
\hline ID (Izquierda Democrática) & 788573 & 17,5 & 23,7 & 4 & 23 & 27 \\
\hline $\begin{array}{l}\text { PRIAN (Partido de Renovación } \\
\text { Institucionalista Acción Nacional) }\end{array}$ & 451838 & 10 & 7,1 & 1 & 18 & 19 \\
\hline PRE (Partido Roldocista Ecuat.) & $429 \quad 522$ & 9,5 & 12,2 & 2 & 25 & 27 \\
\hline $\begin{array}{l}\text { DP-UDC (Democracia Popular } \\
\text { Unidad Demócrata Cristiana) }\end{array}$ & 261133 & 5,8 & 3,2 & 3 & 21 & 24 \\
\hline $\begin{array}{l}\text { MUPP (Movimiento de Unidad } \\
\text { Plurinacional, Pachakutik) }\end{array}$ & 220644 & 4,9 & 3,3 & 3 & 19 & 22 \\
\hline $\begin{array}{l}\text { MPD (Movimiento Popular } \\
\text { Democrático) }\end{array}$ & 171041 & 3,8 & 3,16 & 2 & 9 & 11 \\
\hline $\begin{array}{l}\text { PS-FA (Partido Socialista- } \\
\text { Frente Amplio) }\end{array}$ & 25679 & 0,6 & 1,00 & 0 & 2 & 2 \\
\hline PSP (Partido Sociedad Patriótica) & & & & 0 & 22 & 22 \\
\hline $\begin{array}{l}\text { CFP (Concentración de Fuerzas } \\
\text { Populares) }\end{array}$ & & & & 2 & 4 & 6 \\
\hline $\begin{array}{l}\text { Otros (Movimientos, diversas } \\
\text { organizaciones, otros partidos) }\end{array}$ & 1204850 & 26,6 & 20,35 & 1 & 11 & 12 \\
\hline Votos válidos (positivos) & 4518662 & 100,0 & & & & \\
\hline Blancos & 444694 & 8,2 & 4,00 & & & \\
\hline Nulos & 556762 & 10,2 & 9,00 & & & \\
\hline Total & $\begin{array}{lll}5 & 520 & 118\end{array}$ & 100,0 & & & & \\
\hline
\end{tabular}

constantemente. Su acervo electoral es de alrededor del $10 \%$, sin ninguna alianza y logra electos importantes en la Sierra (prefectura de Imbabura, alcaldía de Latacunga).

Pachakutik (MUPP), partido originalmente formado por los indígenas, mantiene su porcentaje del $5 \%$ a pesar de su pérdida de reconocimiento por haber estado en alianza con el actual gobierno por 6 meses. Su presencia fue mayoritaria en municipios con fuerte población indígena; ahora obtiene 18 municipios y afianza su presencia, al nivel de provincias con 3 prefecturas, gracias a su imagen de partido pluricultural y por haber logrado buenas gestiones locales. Su presencia en la población amazónica es muy redituable; con pocos votos ha logrado puestos importantes.

(3) Los datos definitivos no salen aún del TSE. Nosotros retomamos aquí — con reelaboración nuestra - la base de datos de Carlos Larrea ("Resultados de las Votaciones del 17 de octubre para prefectos en las 22 provincias" y "Resultados de las votaciones del 17 de octubre para alcaldes en 32 cantones", elaborados para la Revista Tramasocial, ILDIS-Instituto Manuel Cordova, nov/04, agregados a partir de los resultados provinciales y cantonales).

(4) Base de datos de TRAMASOCIAl, elaborada por Raúl Borja.

(5) Los datos al nivel de alcaldes comprenden alrededor del $75 \%$ del electorado presente en 32 cantones, 25 de los cuales corresponden a los más populosos e incluyen a las capitales de las 22 provincias. 
La estrategia política del PSC que es, por un lado, alimentar su bastión con el centro más poblado del país que es Guayaquil y, por otro, ganar presencia local en numerosos municipios por pequeños que sean y así alimentar su electorado nacional, continúa dándole buenos resultados. Es el partido que más "progresa" en dotarse de dimensiones "nacionales"; su inversión en el poder local le es doblemente redituable.

Por su parte, la ID refuerza su imagen de partido urbano. El fuerte de este partido es la Sierra y sus centros más poblados. Si bien este acervo no le otorga muchos puestos al nivel "seccional", en cambio le da votos, con ventajas para las presidenciales. Su debilidad es su reducida presencia en La Costa y en áreas rurales.

\section{ALIANZAS POLÍTICAS}

Esta presencia de partidos es concomitante con la desestabilización y rechazo a éstos. Se refleja en el fenómeno de "movimientos políticos", más de 200 a diferentes niveles, y en el de alianzas entre diferentes partidos o listas.

La mayoría de estas alianzas no sigue tendencias orgánicas sino lógicas diversas en las cuales predomina el reconocimiento de personas; sin embargo, en los espacios más urbanos, como Quito o Cuenca, se perciben alianzas de tendencias, un fenómeno de convergencia.

El desprestigio de los partidos ha llevado a su cuestionamiento por estos movimientos o a que las alianzas reduzcan su peso o sean ciertas personalidades locales las que adquieren mayor peso que sus partidos. Hay personalidades que afirman su imagen distanciándose de sus partidos (6) y conforman un "movimiento" ad-hoc con el fin de aglutinar otras fuerzas políticas (7).

51 alcaldías (sobre 219) y 8 prefecturas (sobre 22) han sido elegidas con alianzas.

Estas alianzas locales de las más diversas son vistas como la pérdida de referentes ideológicos o de control de los partidos sobre su nivel local. Pero, puede también ser fruto de dinámicas locales que calzan mal con las de los partidos al nivel nacional. La redefinición y renovada importancia del poder local son mal asimiladas por los partidos.

Paradójicamente, en el sistema político ecuatoriano en que las alianzas deberían predominar, persiste la idea que cada partido debe preservar su espacio en competencia con los demás. Las alianzas en estas elecciones indican que los partidos están reconociendo el espacio de cada cual y el sentido de convergencia, lo cual es un cambio sustantivo en el Ecuador.

\section{6. "MOVIMIENTOS POLÍTICOS"}

Los movimientos políticos son, en general, organizaciones de corta duración. En 2004, la mayoría estuvo en alianzas de derechas. Al inicio del ciclo político, ante la crisis de la izquierda, los "movimientos" eran sobre todo de esta tendencia, ahora es la derecha que pierde cohesión por haber mermado su credibilidad al ser promotora de la modernización en curso, con efectos sociales negativos. Los partidos del centro a la

(6) Fenómeno que ya ha sido descrito por Catherine Conaghan (1995).

(7) Rodrigo Paz, en Quito, con su "Movimiento Quito en Acción” obtuvo el segundo lugar. 
izquierda, en cambio, se recuperan y realinean a su interno. Puede ser un síntoma de un cambio de ciclo político.

Las exigencias para poder presentar una lista electoral son particularmente permisivas, lo cual favorece la multiplicación de listas en coyunturas como la actual, y alimenta aún más el fraccionamiento partidario, la dificultad de convergencia o de consolidación de tendencias y gestión pública (León, 2004; Mejía, 2002; Pachano, 1998; Quintero, 2002; Tanaka, 2003).

\section{LA REELECCIÓN DE ALCALDES Y PREFECTOS}

Un fenómeno nuevo para el Ecuador es la importancia adquirida por la reelección de alcaldes, prefectos y otros representantes locales. Ecuador conocía una altísima rotación de electos, pero en esta ocasión casi la mitad de los prefectos (10) y más del tercio de los alcaldes (83) han sido reelegidos.

Este hecho revela, en primer lugar, la importancia dada a la gestión local. Ante la crisis de funcionamiento del gobierno central, la gestión local e intermedia adquiere importancia. Ella logra mejoras urbanas o de servicios públicos y gracias a la descentralización obtiene recursos adicionales. Los partidos dan ahora más importancia a las elecciones locales para construir una base electoral más firme. Desde hace años, el PSC invierte en este sentido. Sus diputados hacen presiones diversas a los gobiernos para que sus gobiernos locales reciban mayores entradas fiscales. El éxito subsiguiente de sus electos garantizaal PSC mantener su electorado para los puestos nacionales y — como en el caso colombianodisponer de caciques locales que logran un control de largo plazo.

Las mujeres han logrado mayor número de candidatas y electas que en el pasado. Una Ley de Cuotas obliga a incorporar un número creciente de candidatas en cada elección (actualmente $35 \%$ ) lo cual ha contribuido a los resultados actuales. 12 mujeres fueron candidatas a prefectas y 120 a alcaldesas. El número de electas a diversos puestos también se ha incrementado (8).

\section{NORMAS ELECTORALES Y DEMOCRACIA}

Estas elecciones, desligadas de las presidenciales y realizadas con nuevas reglas, han permitido que los aspectos locales adquieran mayor relevancia y han revelado la importancia de las normas del juego electoral. Normas muy restrictivas del gasto electoral limitaban el recurso a la televisión. Su incidencia ha sido significativa en relación a dos criterios indispensables de elecciones en democracias: el acceso a la expresión para las organizaciones políticas en competencia y el derecho de la ciudadanía a ser informada sobre sus propuestas. La libre expresión es indispensable, pero uno puede expresarse sin informar. La cuestión decisiva es cómo llegar a la persona común con las propuestas de cada cual.

La limitación del gasto electoral ha impedido que los más afortunados puedan invadir la televisión con propaganda, favoreciendo así mayor igualdad de condiciones en la competencia con los que disponen de menos recursos. Impedidos de centrar su

(8) No disponemos aún de los cómputos de los resultados electorales según sexo. 
campaña en la propaganda de televisión, los candidatos(as) se han dado modos para informar.

También la ciudadanía buscó mayor información. Los candidatos debieron acercarse más a la población y modificar la distancia ya estatuida por el predominio de la televisión. Los medios de prensa han modificado sus prácticas al verse en la necesidad de abrir su espacio de modo sistemático a todos los candidatos.

Doble fenómeno de democratización, la apertura de la prensa para todos y la mayor equidad en la competencia que han favorecido mayor información para la decisión. Los empresarios de la prensa y los políticos pudientes se oponen vehementemente a estas limitaciones del gasto electoral.

\section{CONCLUSIONES}

No existen modificaciones sustantivas en el espectro político con estas elecciones. No emerge un partido interregional, persiste la tendencia regionalizada de la política ecuatoriana. Tampoco se modifican significativamente las tendencias políticas a pesar de ciertas modificaciones entre los partidos que las conforman.

No obstante, son perceptibles indicios de cambios de un ciclo político, tales como la opción de más estabilidad perceptible con las reelecciones; la reconstitución actual del centro-izquierda y en parte del centro-derecha; la búsqueda de redefinir el juego político perceptible en la profusión de "movimientos" y alianzas de las más diversas; las alianzas que también indican un reconocimiento práctico de la importancia de integrarse y no de persistir cada organización por separado, es un fenómeno de convergencia; por el pragmatismo observado en las propuestas de campaña en contraste con el pasado reciente; por la ratificación de ciertas alianzas propias a tendencias políticas y no circunstanciales; por el rechazo a los partidos y a los "políticos" paralelamente a una preocupación por redefinir sus prácticas con renovadas propuestas.

\section{Referencias citadas}

CONAGHAN, C., 1995 - Politicians Against Parties: Discord and Disconnection in Ecuador's Party System". In: Building Democratic Institutions. Party Systems in Latin America (Mainwaring, Scott, Scully, Timothy, Edits.), Chap. 13; Stanford: Stanford University Press. En español, 2003 - In: Democracia, gobernabilidad y cultura política: 220-259; Quito: FLACSO-Ecuador, )

LEÓN, T., J., 2004 - La democracia real versus la democracia idealizada. Ecuador de 1978 a 2003. POLÍTICA, n' 1; Santiago.

MEJÍA, A., 2002 - Gobernabilidad democrática. Sistema electoral, partidos políticos y pugna de poderes en Ecuador: 1978-1998; Quito: Fundación Konrad Adenauer.

PACHANO, S., 1998 - Democracia sin sociedad. La representación caótica (análisis del sistema electoral ecuatoriano), 108 p.; Quito: FLACSO. Quito, ILDIS, 1996.

QUINTERO, R., 2002 - Entre el hastío y la participación ciudadana. Partidos y elecciones en el Ecuador (2000-2002); Quito: Ediciones Abya Yala.

TANAKA, M., 2003 - La situación de la democracia en Bolivia, Chile y Ecuador a inicios de siglo; Lima: CAJ. 